\title{
Linking the sub-Saharan and West Eurasian gene pools: maternal and paternal heritage of the Tuareg nomads from the African Sahel
}

\author{
Luísa Pereira ${ }^{1,2}$, Viktor Černý ${ }^{\star 3}$, María Cerezo $^{4}$, Nuno M Silva ${ }^{1}$, Martin Hájek $^{3}$, Alžběta Vašíková $^{5}$, \\ Martina Kujanová ${ }^{6}$, Radim Brdička ${ }^{5}$ and Antonio Salas ${ }^{4}$
}

The Tuareg presently live in the Sahara and the Sahel. Their ancestors are commonly believed to be the Garamantes of the Libyan Fezzan, ever since it was suggested by authors of antiquity. Biological evidence, based on classical genetic markers, however, indicates kinship with the Beja of Eastern Sudan. Our study of mitochondrial DNA (mtDNA) sequences and $Y$ chromosome SNPs of three different southern Tuareg groups from Mali, Burkina Faso and the Republic of Niger reveals a West Eurasian-North African composition of their gene pool. The data show that certain genetic lineages could not have been introduced into this population earlier than $\sim 9000$ years ago whereas local expansions establish a minimal date at around 3000 years ago. Some of the mtDNA haplogroups observed in the Tuareg population were involved in the post-Last Glacial Maximum human expansion from Iberian refugia towards both Europe and North Africa. Interestingly, no Near Eastern mtDNA lineages connected with the Neolithic expansion have been observed in our population sample. On the other hand, the $Y$ chromosome SNPs data show that the paternal lineages can very probably be traced to the Near Eastern Neolithic demic expansion towards North Africa, a period that is otherwise concordant with the above-mentioned mtDNA expansion. The time frame for the migration of the Tuareg towards the African Sahel belt overlaps that of early Holocene climatic changes across the Sahara (from the optimal greening $\sim 10000$ YBP to the extant aridity beginning at $\sim 6000 \mathrm{YBP}$ ) and the migrations of other African nomadic peoples in the area.

European Journal of Human Genetics (2010) 18, 915-923; doi:10.1038/ejhg.2010.21; published online 17 March 2010

Keywords: Tuareg; genetic diversity; phylogeography

\section{INTRODUCTION}

The Tuareg call themselves Kel Tamasheq (people of the Tamasheq language) or Imashaghen (free people). The Tamasheq tongue is a Berber language belonging to the Afro-Asiatic phylum. The Tuareg maintain a nomadic and/or semi-nomadic lifestyle in the Central Sahara and adjacent regions of the African Sahel, where they number about 1262000 in total. Their contemporary geographic distribution is shown in the upper map in Figure 1.

The 5th century $\mathrm{BC}$ Greek historian Herodotus suggested that the ancestral homeland of the ancient Tuareg (ie Garamantes) was the Libyan Fezzan. ${ }^{1}$ It has been suggested that subsequent to the camel being adopted for Saharan trade in the 1st or 2nd century AD, the area of Tuareg influence expanded further to the south. Oral accounts and sparse written records in Tifinagh (the script of the Tamasheq language) date back to 14th century $\mathrm{AD}$ when the first caravan traders were documented in the Air Mountains. Hereafter, it seems that from the 17th century onwards the increasingly frequent invasions of North Africa by various Arabic tribes drove the Tuareg yet further southward to the African Sahel.
Since the beginning of European explorations of the Sahara and the Sahel, the Tuareg have been known mainly as caravan traders linking the sub-Saharan and Mediterranean cultures. Their contact with the various sub-Saharan peoples was not always peaceful and they were known to take war captives. Centuries of mutual contact led to substantial assimilation of others into the Tuareg population.

Carrying out biological or genetic investigations of the Tuareg has not always been easy because of their demanding lifestyle and their often negative attitude to the European colonists. Cavalli-Sforza et al, ${ }^{2}$ whose synthesized study of classical protein and serological markers is well known, noticed a genetic link between the Tuareg and Beja from Eastern Sudan. The fact that the genetic distances between the Tuareg and Berber/North-western Africans were larger than that between the Tuareg and Beja, provides a picture of a common origin and population separation at some point more than 5000 years ago. Interestingly, both people are also pastoralist and speak Afro-Asiatic languages, even if the Beja language (Bedawi), with its four dialects, belongs to the Cushitic branch, whereas Tamasheq belongs to the Berber branch. The fact that these two peoples today speak different languages might be

\footnotetext{
${ }^{1}$ Instituto de Patologia e Imunologia Molecular da Universidade do Porto (IPATIMUP), Porto, Portugal; ${ }^{2}$ Faculdade de Medicina da Universidade do Porto, Porto, Portugal; ${ }^{3}$ Archaeogenetics Laboratory, Institute of Archaeology of the Academy of Sciences of the Czech Republic, Prague, The Czech Republic; ${ }^{4}$ Unidade de Xenética, Departamento de Anatomía Patolóxica e Ciencias Forenses, Facultade de Medicina, Instituto de Medicina Legal, Universidade de Santiago de Compostela, Galicia, Spain; ${ }^{5}$ Institute of Hematology and Blood Transfusion, Prague, The Czech Republic; ${ }^{6}$ Department of Anthropology and Human Genetics, Faculty of Science, Charles University, Prague, The Czech Republic ${ }^{*}$ Correspondence: Dr V Černý, Archaeogenetics Laboratory, Institute of Archaeology of the Academy of Sciences of the Czech Republic, Letenska 4, 118 01, Prague 1, The Czech Republic.

Tel: +420 2570 14304; Fax: +420 2575 32288; E-mail: cerny@aup.cas.cz
}

Received 21 July 2009; revised 15 January 2010; accepted 20 January 2010; published online 17 March 2010 

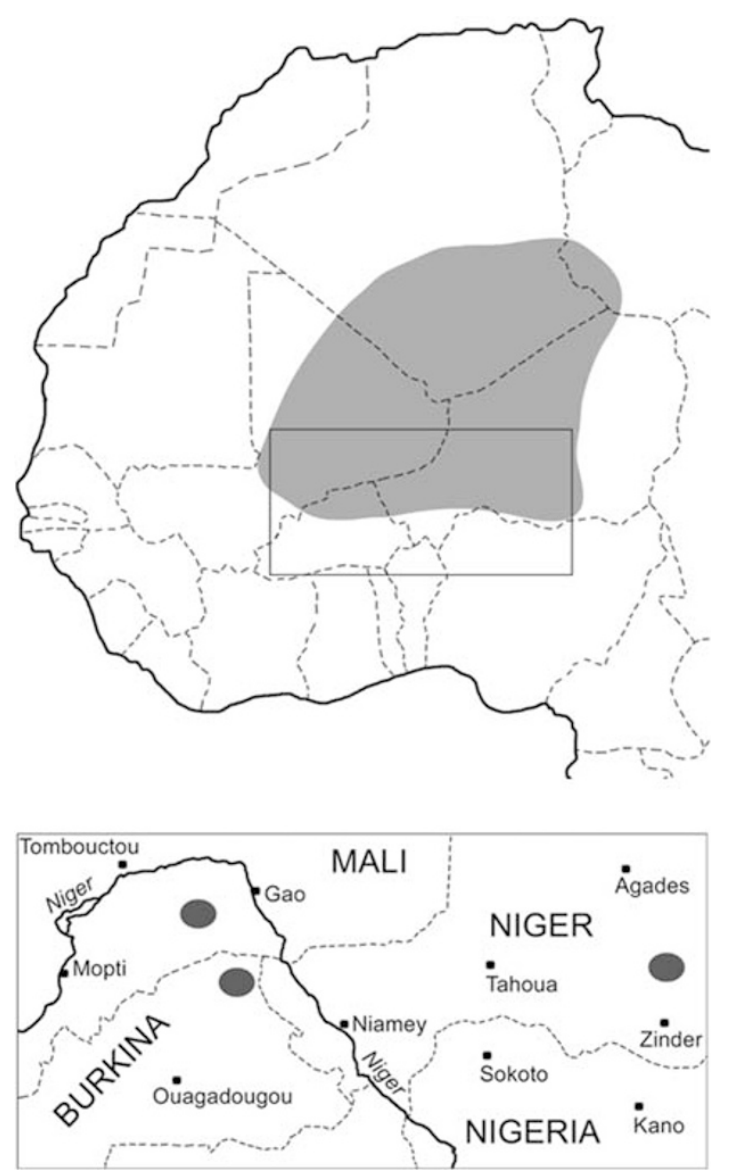

Figure 1 The geographical location of southern Tuareg populations, including the ones studied here: TTan in the Republic of Niger, TGor in Burkina Faso and TGos in Mali.

explained either by the Tuareg having acquired the Berber language during their westwards migration, or possibly by the Beja coming under the influence of some Eastern African peoples as language shift is a relatively common phenomenon.

Among the first African mitochondrial DNA (mtDNA) sequences were those from data sets ${ }^{3,4}$ obtained mostly from Tuareg living in Niger and Nigeria, and which revealed a rather sub-Saharan affinity of their population. More recently, however, a study based on 129 Tuareg samples from two villages of the Libyan Fezzan, stressed a high frequency but concomitant low diversity of the West Eurasian component, bearing only haplogroups $\mathrm{H} 1, \mathrm{~V}$ and M1. The sub-Saharan component of the Libyan Tuareg was more diversified but predominantly represented by only two haplogroups (L2al and L0ala). The Tuareg population from Libya was homogenous with very low estimates of haplotype diversity suggesting high genetic drift. ${ }^{5}$

The above-mentioned studies have thus revealed a dual influence in the genetic make-up of this African people. In this study, we provide new mtDNA and Y chromosome data sets of three unrelated Tuareg groups from three different countries (Niger, Mali and Burkina Faso). At the same time, we try to unravel the questions of their genetic origin, the mutual relationships among their sub-populations as well as possible links to neighbouring populations. The genetic heritage of the Tuareg population is analysed within the context of the West Eurasian versus sub-Saharan contributions to their gene pool.

\section{MATERIALS AND METHODS}

\section{Subjects}

The biological samples (buccal swabs) were obtained from three different groups of self-identified Tuareg (90 unrelated individuals in total). One population sample $(n=38)$ was secured in Burkina Faso around the village Gorom-Gorom (further referred to as TGor). The second sample $(n=31)$ was taken in the Republic of Niger in the vicinity of Tanut (TTan). The third sample ( $n=21)$ was collected in Mali near Gossi (TGos). The samples from Mali and Burkina Faso are geographically relatively close to each other as they are located within the bend of the Niger River, whereas the sample collected in the central part of the Republic of Niger is located some $1500 \mathrm{~km}$ eastward (Figure 1). The field sampling was undertaken with the collaboration of local Tuareg assistants. Of these 90 healthy and unrelated individuals, 47 were male and 43 were female. Oral informed consent was obtained from all participants in the study and research permits were obtained from the Ministries of Education and/or Health in all the three countries.

\section{Laboratory analyses}

DNA extractions and PCR amplifications of mtDNA hypervariable segments I and II (HVS-I and HVS-II) were carried out as in earlier studies. ${ }^{6,7}$ Amplicons were purified and sequenced using forward PCR primers. In some cases the reverse primer was also used for sequencing (due to for example, the presence of poly-C stretches between nt 16184 and 16193). In some samples, SNP testing was analysed through matrix-assisted laser desorption/ionization time-of-flight mass spectrometry and minisequencing. ${ }^{7,8}$ Whole genome sequencing of mtDNAs affiliated by D-loop to the haplogroup M1 was undertaken following the protocols reported elsewhere. ${ }^{7,9-11}$

For the detection of Y chromosome SNP polymorphisms, the Signet Y-SNP Identification System v 2.0 (Marligen, Rockville, MD, USA) was used. All the samples were first analysed by A-R multiplex (polymorphisms M122, M168, M175, M207, M304, M343, M45, M89, M96 and M9), differentiating main evolutionary branches of Y chromosome phylogeny. ${ }^{12}$ Subsequently, samples belonging to haplogroup E were further analysed for polymorphisms DYS391, M2, M33, M35, M58, M75, M78, M81 and M123.

\section{Haplogroup nomenclature}

mtDNA classification into haplogroups $\mathrm{L}, \mathrm{H}, \mathrm{U}$ and $\mathrm{M}$ was carried out in accordance with the most recent phylogenetic studies of Salas et al, ${ }^{13}$ Kivisild et $\mathrm{al}^{14}$ and Behar et $a l^{15}$ for L; Olivieri et al $^{16}$ for $\mathrm{U}$ and $\mathrm{M}$; and Achilli et $a l^{17}$ for $\mathrm{H}$ (see also van Oven and Kayser, 2009). ${ }^{18}$ The numbering is consistent with the revised Cambridge Reference Sequence. ${ }^{19}$ The three complete mtDNA sequences have been deposited in GenBank (accession numbers GQ377749; GQ377750; and GQ377751). For the Y chromosome SNP affiliation, the nomenclature of Karafet et $a^{12}$ was followed.

\section{Statistical and phylogenetic analyses}

Analysis of population structure and molecular diversity measures was calculated by using Arlequin software version 3.0. ${ }^{20}$ Two-tailed Fisher's exact test $P$-values of $2 \times 2$ contingency tables were calculated in DnaSP. ${ }^{21} F_{\text {ST }}$ genetic distances calculated by Arlequin were subsequently visualized in multidimensional scaling (MDS) by means of SPSS 10.0 software (SPSS Inc, Chicago, IL, USA). Extensive data sets of both mtDNA sequences and Y-SNPs were used to characterize the Tuareg diversity within Mediterranean and sub-Saharan population contexts (see Supplementary Material SM1 and SM2).

Phylogenetic reconstruction of mtDNA diversity was based on both HVS-I and complete sequences. The dates of the most recent common ancestor of specific subclusters in the phylogeny were estimated using $\rho .^{22}$ The average number of transitions from the ancestral haplotype to all haplotypes in the cluster, for both coding (between positions 577 and 16023) and HVS-I (between positions 16090 and 16365) regions, was considered with respect to mutation rate estimates of 5138 years $^{23}$ and 20180 years per transition ${ }^{24}$ within the region, respectively. Standard errors were calculated as in Saillard et al. ${ }^{25}$ Recently, updated mutation rates published by Soares et a ${ }^{26}$ were also used for the entire molecule (1 mutation every 3624 years) and synonymous substitutions ( 1 mutation every 7884 years). As the mutation rate determined by these authors for the HVS-I (between positions 16090 and 16365) region, 
however, is very similar to the one used above ( 1 transition every 20129 years versus 20180 years) the calculations overlapped and we present only those estimated with the original $\rho$ mutation rate of 1 substitution every 20180 years.

\section{Interpolation maps}

To determine and visualize the geographical distribution of haplogroups $\mathrm{H} 1$, $\mathrm{H} 3$ and V, we drew interpolation maps using the 'Spatial Analyst Extension' of ArcView version 3.2 (http://www.esri.com/software/arcview/). Inverse distance weighted option that we used assumes that each input point has a local influence that diminishes with distance. The geographic location used is the centre of the distribution area, from where the individual samples of each population were collected. Comparative data for $\mathrm{H} 1$ and $\mathrm{H} 3$ were taken from Finnila et al, ${ }^{27}$ Herrnstadt et al, ${ }^{28}$ Pereira et al, ${ }^{29}$ Cherni et $a l^{30}$ and Ennafaa et $a l^{31}$ and those for haplogroup V from Torroni et al, ${ }^{10}$ Pereira $e t$ al, ${ }^{32}$ Behar et $a^{33}$ and Cherni et al. ${ }^{30}$

\section{RESULTS}

\section{The mtDNA pool of the Tuareg}

The polymorphisms present in the 90 Tuareg individuals led to the identification of 53 different D-loop haplotypes (Table 1). As can be seen in the network based only on HVS-I diversity (Supplementary Material SM3), for which only 33 different haplotypes are observed, there are varying degrees of sharing of haplotypes among the analysed groups: only one belonging to haplogroup $\mathrm{H}$ was shared by all three groups; two haplotypes were shared by TGos-TGor and TGos-TTan; and three haplotypes were shared by TGor-TTan. Only 18 of the 33 haplotypes are unique, what is a rather low proportion when compared to most African samples. ${ }^{32}$ This is further corroborated by haplotype diversities in the three Tuareg samples, which are lower as compared with other populations - especially in the two groups of the Niger bend $(0.861 \pm 0.027$ in TGor; $0.910 \pm 0.037$ in TGos; and $0.963 \pm 0.020$ in TTan; see Supplementary Material SM4).

A total of $48 \%$ of the mtDNA haplotypes observed in the Tuareg populations could be ascribed to sub-Saharan haplogroups. Another $39 \%$, however, were of West Eurasian ancestry (non-L types in Table 1), which is a substantial proportion considering the subSaharan geographical location. In fact, it has been observed that in typical North African populations there is a gradient of increasing frequency of West Eurasian lineages ranging from around 50-75\% in the northernmost locations. ${ }^{34}$ The Tuareg's neighbours, however, have a markedly smaller proportion of West Eurasian haplotypes (22\% in Western Chad Arabs, $8 \%$ in Shuwa Arabs from North-eastern Nigeria, $7 \%$ in the Buduma from South-eastern Niger and $6 \%$ in the Kanuri from North-eastern Nigeria). ${ }^{35}$ The remaining $13 \%$ of Tuareg haplotypes belong to the typical East African haplogroup M1.

Furthermore, we noticed some differences in the distribution of West Eurasian mtDNA haplogroups between Tuareg groups. Most of the West Eurasian haplogroups ( 30 out of 35 sequences, amounting to 6 out of 9 HVS-I haplotypes) and the East African M1 (11 out of 12 sequences but amounting to only 2 out of 3 HVS-I haplotypes) are observed in the two Tuareg populations - TGos and TGor - located within the bend of the Niger. Tuareg from the Republic of Niger, TTan, have much higher proportion of sub-Saharan (81\%) haplogroups than of West Eurasian (16\%) and East African (3\%) ones. These differences in haplogroup distribution led to statistically significant genetic distances when comparing HVS-I haplotypes between Tuareg from Mali (TGos) with those from the Republic of Niger (TTan) $\left(F_{\mathrm{ST}}=0.048\right.$; unadjusted $P$-value $\left.=0.009\right)$, as well as Tuareg from Burkina Faso (TGor) with those from the Republic of Niger (TTan) $\left(F_{\mathrm{ST}}=0.064\right.$; unadjusted $P$-value $\left.=0.000\right)$, whereas Tuareg from Mali (TGos) and from Burkina Faso (TGor) are not statistically different $\left(F_{\mathrm{ST}}=0.012\right.$; unadjusted $P$-value $\left.=0.234\right)$. Similarly, analysis of MDS based on $F_{\mathrm{ST}}$ distances and using a large database of West Eurasian and African mtDNA sequences has shown a very good separation of the sub-Saharan and West Eurasian-North African gene pools (Figure 2). Only some East African populations are closer to the West Eurasian samples, respectively, to the North African populations analysed here. This picture is a good representation of $F_{\mathrm{ST}}$ values as the normalized raw stress is very low (0.01165). However, the analysed Tuareg populations are divided between two gene pools: like the sample from Libya, ${ }^{5}$ the groups located within the bend of Niger (TGor and TGos) fall into the West Eurasian gene pool, whereas the Tuareg from the Republic of Niger (TTan) and the Tuareg sample from the Watson's data set $^{3,4}$ are permeated by the sub-Saharan mtDNA gene pool.

The West Eurasian component observed in the Tuareg is highly interesting. A major proportion (94\%) could be allocated to haplogroups $\mathrm{H} 1, \mathrm{H} 3$ and V, West Eurasian lineages of Iberian origin that spread to Europe $e^{7,10,17,26,29,36}$ and most probably North Africa ${ }^{30,31}$ with the improvement of the climatic conditions after the retreat of the ice sheets 15000-13000 years ago. The interpolation maps of these lineages across North Africa and Europe (Supplementary Material SM5) clearly place the Tuareg population in the path of the southern African edge of post-Last Glacial Maximum expansions. The H1 haplogroup (Supplementary Material SM5A and SM5B, with and without the outlier Norway, respectively) is as frequent in our southern Tuareg groups as in Libya and the centre of the dispersion within the Iberian Peninsula. The H3 haplogroup is almost vestigial in Tuareg (Supplementary Material SM5C), having the highest observed frequencies outside of Iberia in Algeria and Tunisia. Again for haplogroup V, Tuareg present frequencies as high as in the Basque country (Supplementary Material SM5D).

Both $\mathrm{H} 1$ and $\mathrm{H} 3$ commonly display rather low diversity in the D-loop region, but the Tuareg haplotypes belonging to haplogroup $\mathrm{V}$ have a specific diagnostic mutation - the transition at position 16234 . All the Tuareg V haplotype samples collected in Burkina Faso and the Republic of Niger (three haplotypes observed in 11 individuals) bear this mutation together with the defining substitution at position 16298, This polymorphism is present in two of the five $\mathrm{V}$ haplotypes observed in the recently published Libyan Tuaregs. ${ }^{5}$ This fact seems to point to a founder effect in haplogroup V occurring in our southern Tuareg population; the further presence of two other polymorphisms in two V samples (substitutions at positions 16189 and 16293) allows a very preliminary estimation for the Time to the Most Recent Common Ancestor (TMRCA) of this Tuareg V sub-lineage at around $3600 \pm 2600$ years ago or at a maximum of 8800 years ago if using a 95\% confidence interval (see Supplementary Material SM6 for the network).

Another very interesting characteristic of the West Eurasian mtDNA pool in the Tuareg population as a whole (including Watson's and Ottoni's data sets) is the total absence of so-called Neolithic haplogroups derived from the branch JT, which are otherwise common in Near Eastern, North African, Mediterranean and even some East African populations. The virtual absence of these lineages in the Tuareg is statistically significant when comparing the frequency of these lineages in Morocco $^{34}$ ( $18 \%$; unadjusted $P$-value $\left.=0.000\right)$, Tunisia ${ }^{30}$ $(12 \%$; unadjusted $P$-value $=0.000)$ and Egypt $^{37}$ (29\%; unadjusted $P$-value $=0.000)$. Notice also the absence of the haplogroup U6, which is present mainly in Berbers but also in several others North African groups. ${ }^{13,16,38}$

The sub-Saharan mtDNA pool of the Tuareg is composed of various lineages from the major L-type haplogroups including: $2.3 \%$ of $\mathrm{L} 0$; $14.0 \%$ of L1; $58.1 \%$ of $\mathrm{L} 2 ; 23.3 \% \mathrm{~L} 3$; and $2.3 \%$ of $\mathrm{L} 4$. We assayed to 


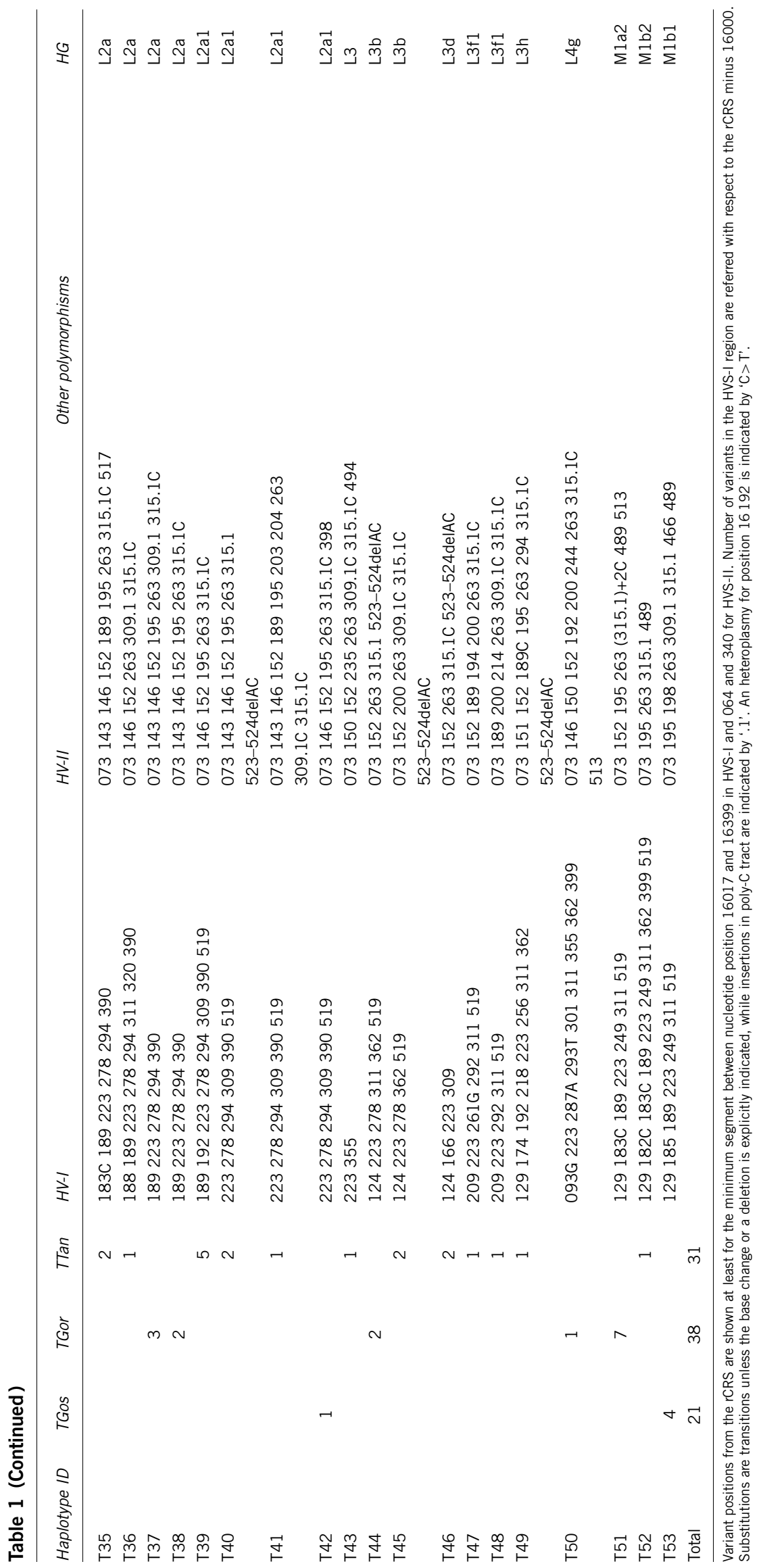




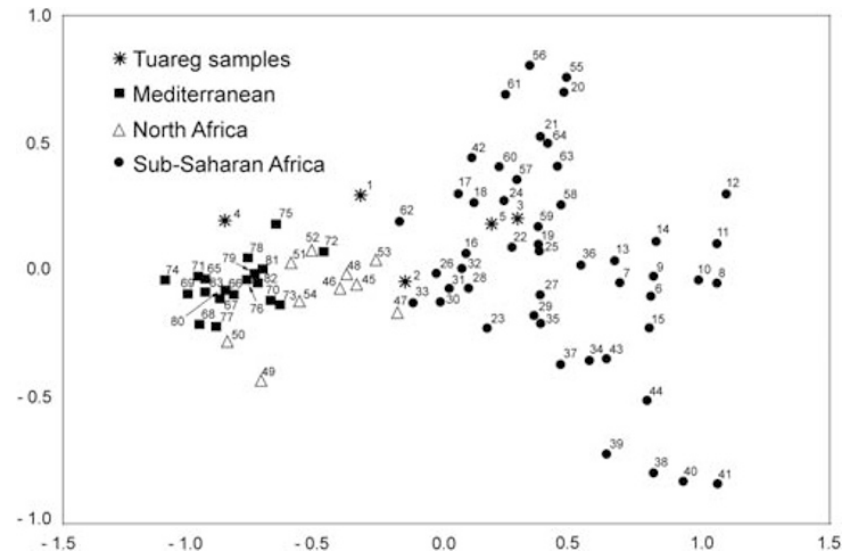

Figure 2 MDS plot of $F_{\mathrm{ST}}$ genetic distances calculated from HVS-I mtDNA sequences. For numbers see Supplementary Material SM1.

search for haplotype matches in an extensive database of 7211 individuals from all over Africa (Table 2). The most ancient lineages L0ala and L1c, characteristic of east/southeast $\mathrm{Africa}^{13}$ and the Pygmies, ${ }^{39}$ respectively, were each observed in only one individual. The highly frequent African haplogroup L2, and specifically its dominant clade L2a, is also dominant in Tuareg - it is probable that some branches of L2a were involved in the Bantu expansion towards the African south ${ }^{13,40}$ and many matches are observed for these haplotypes all over the continent. Curiously, the two L2a lineages having substitutions at positions 16192 and 16193 , respectively, have no match in Africa. As far as the L3 macrohaplogroup is concerned, the two L3b haplotypes observed in the Tuareg are widespread throughout the continent, but one of the L3f1 haplotypes (T47 in Table 1) has no matches. Both are included in the L3f1 sub-haplogroup, which is quite frequent and widespread, and which very probably originated in East Africa. No L3f3, a typical marker of the Chadic migration, ${ }^{41}$ has been observed in the Tuareg.

In summary, the matches between Tuareg sub-Saharan haplotypes and the diverse African regions were, after correcting for the size for each region, 5.6\% with Africa-Central; 4.3\% with Africa-East; 3.4\% with Africa-North; $1.1 \%$ with Africa-South; $4.3 \%$ with Africa-southeast; $4.5 \%$ with Africa-southwest; $12.7 \%$ with Africa-West; and $13.4 \%$ with Africa-westcentral. The West Africa or West-Central African lineages thus are clearly dominant in the extant Tuareg.

The influence of East Africa in the Tuareg can be investigated more directly through haplogroup M1. ${ }^{16}$ As concerns the finer classification of Tuareg M1 haplotypes, two of them ( 5 sequences out of 12) belong to M1b, which has a clear Mediterranean distribution, pointing to North Africa as its most probable gateway to the Tuareg. This finding is inconsistent with the absence of U6, which is believed to have entered Africa together with M1 in a back migration from western Eurasia around 45000 years ago. The time estimate for M1b, based on the coding region, is $23400 \pm 5600$ years, ${ }^{16}$ placing its origin in the Early Upper Palaeolithic. More promising in ascertaining Eastern African origin is another haplotype observed in seven Tuareg individuals from Burkina Faso belonging to haplogroup Mla, which, though being considered dominant in East Africa ${ }^{42}$ also spread to the Mediterranean, and which has a total age of $28800 \pm 4900$ years. ${ }^{16}$ We performed the complete sequencing of three individuals, which despite not displaying any difference at HVS-I and HVS-II, might present some substitutions in the coding region, allowing for a better estimate of a TMRCA. These three samples, however, did not bear any difference even when sequencing the complete genome. Nonetheless, when taken together with the other M1a2a individuals (Figure 3) reported in Olivieri et al $^{16}$ (sample 1 in Figure 3, accession number EF060335; sample 2, accession number EF060336), González et al ${ }^{43}$ (sample 3; accession number DQ779927) and Maca-Meyer et al ${ }^{44}$ (sample 4; accession number AF381984) allowed an age estimation for this sub-haplogroup at $8000 \pm 2400$-years old based on diversity in the coding region. We checked the TMRCA using Soares et a ${ }^{26}$ mutations rates for the entire molecule and for the synonymous substitutions, obtaining, respectively, the following concordant dates: $10400 \pm 2300$ and $10200 \pm 3400$. Notice, however, that all the other four M1a2a complete sequences were observed in the Mediterranean region and in Table 2 the HVS-I motif observed in Tuareg has 10 perfect matches in the Africa-North data set and one in Africawestcentral.

\section{Y chromosome pool in Tuareg}

From the 20 branches of the Y chromosome tree, which could be discriminated by the analyses performed, only 7 were observed in our Tuareg population sample (Supplementary Material SM7). Again, from this perspective of $\mathrm{Y}$ chromosome diversity, TTan is closer to sub-Saharan populations than the other two Tuareg populations, presenting $5.6 \%$ of the old $\mathrm{AB}$ lineages and $44.4 \%$ of E1bla, whereas TGor and TGos have, respectively, 16.7 and 9.1\% of E1bla. Curiously, TTan also presents the highest frequency $(33.3 \%)$ of West Eurasian R1b lineages whereas TGor presents only $5.6 \%$ of lineage $\mathrm{K}^{\star}$ $(\mathrm{xO}, \mathrm{P})$, and TGos presents none. There were no instances of the Eurasian $\mathrm{J}$ haplogroup in the Tuareg, which is otherwise frequent in North Africa (an average of $20 \%$; see Arredi et $a l^{45}$ ), and attains the highest frequency in the Middle East (around 50\%; see Semino et al) ${ }^{46}$.

The dominant haplogroup in TGor $(77.8 \%)$ and TGos $(81.8 \%)$ is Elblb1b, which has a much lower frequency in TTan $(11.1 \%)$. This haplogroup reaches a mean frequency of $42 \%$ in North Africa, decreasing in frequency from $76 \%$ in Morocco to $~ 10 \%$ in Egypt. ${ }^{45}$ Arredi et $a l^{45}$ dated this haplogroup in North Africa from 2800 to 9800 YBP, associating its expansion with the Neolithic demic diffusion of Afro-Asiatic-speaking pastoralists from the Middle East.

The low level of diversity attained in the Tuareg populations (see Supplementary Material SM8) is consistent with a model of population constancy, although it can also be due in part to the ascertainment bias in the selection of a few Y-SNPs. Haplotype diversities and mean number of pairwise differences were very low in TGor and TGos, being among the lowest values observed in many populations, but TTan showed much higher levels of diversity.

MDS of $F_{\mathrm{ST}}$ distances based on available Y-SNP West Eurasian and African population data sets shows, as in the case of mtDNA, separation of the West Eurasian-North African and sub-Saharan populations (Figure 4). A certain separation between the Iberian and Near Eastern groups can be explained by the absence of samples from the Central Mediterranean for the Y-NRY data set. However, though the Tuareg groups from the Niger bend (TGor and TGos) belong clearly on the West Eurasian side, the Tuareg from central Niger lean towards sub-Saharan variability.

\section{DISCUSSION}

The Tuareg have a nomadic lifestyle and according to some demographic reports they show reduced fertility in comparison with their neighbours. ${ }^{47-49}$ The data observed here for mtDNA and Y-SNP diversities are concordant with those independent reports, especially for the Tuareg living within the bend of the Niger. 
Table 2 HVS-I haplotype match for the haplotypes observed in Tuaregs samples and an extensive African database (composed of the following geographical regions: Central (AF-C), East (AF-E), North (AF-N), South (AF-S), Southeast (AF-SE), Southwest (AF-SW), West (AF-W) and West-Central (AF-WC)). Number of variants in the HVS-I region are referred with respect to the rCRS minus 16000

\begin{tabular}{|c|c|c|c|c|c|c|c|c|c|c|c|}
\hline Haplotypes & Tuareg & $A F-C$ & $A F-E$ & $A F-N$ & $A F-S$ & $A F-S E$ & $A F-S W$ & $A F-W$ & $A F-W C$ & Totals & Haplogroup \\
\hline rCRS & 14 & 0 & 4 & 193 & 2 & 0 & 1 & 7 & 5 & 226 & $\mathrm{H} ?$ \\
\hline 093126145187189223264270278293311 & 1 & 0 & 0 & 0 & 0 & 0 & 0 & 1 & 0 & 2 & L1b \\
\hline 093189192223278294311 & 3 & 0 & 0 & 0 & 0 & 0 & 0 & 0 & 0 & 3 & $\mathrm{~L} 2 \mathrm{a}$ \\
\hline 093189193223278294311 & 3 & 0 & 0 & 0 & 0 & 0 & 0 & 0 & 0 & 3 & $\mathrm{~L} 2 \mathrm{a}$ \\
\hline 093260343 & 1 & 0 & 0 & 0 & 0 & 0 & 0 & 0 & 0 & 1 & U3a \\
\hline 093G 223 287A 293T 301311355362 & 1 & 2 & 0 & 0 & 0 & & 0 & 0 & 9 & 12 & L4g \\
\hline 124166223309 & 2 & 0 & 0 & 0 & 0 & 0 & 0 & 0 & 0 & 2 & L3d \\
\hline 124223278311362 & 2 & 11 & 3 & 0 & 0 & 3 & 1 & 2 & 14 & 36 & $\mathrm{~L} 3 \mathrm{~b}$ \\
\hline 124223278362 & 2 & 5 & 3 & 4 & 0 & 1 & 2 & 67 & 34 & 118 & $\mathrm{~L} 3 \mathrm{~b}$ \\
\hline 126172187189223264270278293311 & 1 & 2 & 0 & 1 & 0 & 0 & 0 & 0 & 3 & 7 & L1b1 \\
\hline 126187189223264270278293311 & 3 & 26 & 2 & 15 & 0 & 1 & 0 & 47 & 37 & 131 & L1b1 \\
\hline $129148168172187188 G 189193223230278293311320$ & 1 & 0 & 0 & 0 & 0 & 0 & 0 & 0 & 0 & 1 & LOala \\
\hline 129174192218223256311362 & 1 & 0 & 0 & 0 & 0 & 0 & 0 & 0 & 0 & 1 & L3h \\
\hline 129 182C 1831189223249311362 & 1 & 0 & 0 & 0 & 0 & 0 & 0 & 0 & 0 & 1 & M1b2 \\
\hline $129183 \mathrm{C} 189$ & 1 & 0 & 0 & 0 & 0 & 0 & 0 & 0 & 0 & 1 & $\mathrm{H} 1$ \\
\hline $129183 \mathrm{C} 189215223261278294311360$ & 1 & 0 & 0 & 0 & 0 & 0 & 0 & 0 & 0 & 1 & L1c \\
\hline $129183 C 189223249311$ & 7 & 0 & 0 & 10 & 0 & 0 & 0 & 0 & 1 & 18 & M1a2 \\
\hline 129185189223249311 & 4 & 0 & 0 & 5 & 0 & 0 & 0 & 0 & 0 & 9 & M1b1 \\
\hline 169223239278294309 & 1 & 0 & 0 & 0 & 0 & 0 & 0 & 0 & 0 & 1 & $\mathrm{~L} 2 \mathrm{a}$ \\
\hline 172213223261278318 & 1 & 0 & 0 & 0 & 0 & 0 & 0 & 0 & 0 & 1 & $\mathrm{~L} 2 *$ \\
\hline 183C 189223278294 & 2 & 0 & 0 & 0 & 0 & 0 & 0 & 0 & 1 & 3 & $\mathrm{~L} 2 \mathrm{a}$ \\
\hline 188189223278294311320 & 1 & 0 & 0 & 1 & 0 & 0 & 0 & 0 & 0 & 2 & $\mathrm{~L} 2 \mathrm{a}$ \\
\hline 189 & 5 & 0 & 0 & 7 & 0 & 0 & 0 & 0 & 0 & 12 & $\mathrm{H}$ \\
\hline 189192223278294309 & 5 & 14 & 9 & 8 & 3 & 3 & 3 & 19 & 24 & 88 & L2a1 \\
\hline 189223278294 & 5 & 0 & 4 & 1 & 0 & 0 & 0 & 3 & 0 & 13 & L2a \\
\hline 189234298 & 1 & 0 & 0 & 0 & 0 & 0 & 0 & 0 & 0 & 1 & V \\
\hline $209223261 G 292311$ & 1 & 0 & 0 & 0 & 0 & 0 & 0 & 0 & 0 & 1 & L3f1 \\
\hline 209223292311 & 1 & 1 & 12 & 4 & 0 & 0 & 0 & 4 & 18 & 40 & L3f1 \\
\hline 223278294309 & 4 & 18 & 4 & 12 & 0 & 10 & 1 & 38 & 20 & 107 & L2a1 \\
\hline 223355 & 1 & 0 & 0 & 0 & 0 & 0 & 0 & 3 & 1 & 5 & L3 \\
\hline 234293298 & 1 & 0 & 0 & 0 & 0 & 0 & 0 & 0 & 0 & 1 & V \\
\hline 234298 & 9 & 0 & 0 & 0 & 0 & 0 & 0 & 0 & 0 & 9 & V \\
\hline 311 & 3 & 0 & 4 & 19 & 1 & 0 & 0 & 0 & 0 & 27 & U3?/H \\
\hline Partial totals & 90 & 79 & 45 & 280 & 6 & 18 & 8 & 191 & 167 & 884 & \\
\hline Totals (sample sizes per continental region) & 90 & 1404 & 862 & 1360 & 266 & 416 & 157 & 1454 & 1202 & 7211 & \\
\hline
\end{tabular}

The overall West Eurasian mtDNA gene pool in the Tuareg population as a whole (H1, H3 and V) seems to favour a North African heritage. ${ }^{50}$ The only exception is the absence of the otherwise rare U5b that might have rather come to Africa through the Near East, and then drifted to higher frequencies only in some isolated populations such as in the Egyptian oasis Siwa. ${ }^{51}$ The absence of U6 can further be explained by genetic drift during the expansion of this haplogroup within North Africa. ${ }^{51}$ Note that U6 was observed at low frequencies in several population groups from the Chad Basin, such as in the Nilo-Saharan Kanuri and the Afro-Asiatic Masa. ${ }^{35}$

Relationships with the peoples of Eastern Sudan (the Beja) as pointed to by the study of classical genetic markers ${ }^{2}$ cannot yet be disregarded here as there is still no mtDNA of the Beja people available for study. However, according to historical reports, the origin of the Beja is more likely to be traceable to the Arabian Peninsula ${ }^{52}$ and the West Eurasian mtDNA lineages seen in the Tuareg have a rather Iberian affiliation in the post-LGM, and probably expanded to North Africa first. ${ }^{30,31}$ The weak Eastern African influence in Tuareg is further supported by the M1 haplotypes belonging to the lineages characteristic of the later Mediterranean expansion (M1b and M1a2a) and the presence of very few matches for sub-Saharan L haplotypes with East Africa. The main post-LGM Eurasian and M1a2a lineages found in the Tuareg favour North African origin with migration to its southern location in the Sahel between $\sim 9000$ and $\sim 3000$ years ago. The upper time limit is defined by the age of the M1a2a, (estimated here from the coding region diversity observed in the three Tuareg, two North and two south Mediterranean individuals at $8000 \pm 2400$ ), and by the upper $95 \%$ confidence interval for the Tuareg $\mathrm{V}$ lineages having polymorphism 16234 (8800 years ago); the lower limit is defined by the age of the Tuareg $\mathrm{V}$ lineages having polymorphism 16234 (3600 years ago).

The dates obtained from the genetic data coincide well with climatic changes in the Sahara, which resulted in repopulation during the first half of the Holocene when by $\sim 10000$ YBP (the Holocene climatic optimum) humid conditions and greening were established. The climatic optimum lasted until $\sim 6000$ YBP, when the shift towards more permanent aridity occurred, culminating with the formation of the current Sahara desert. This desertification could have entrapped Tuareg populations coming from North Africa to the Sahel belt together with other pastoralists such as the Chadic speaking peoples ${ }^{41}$ 


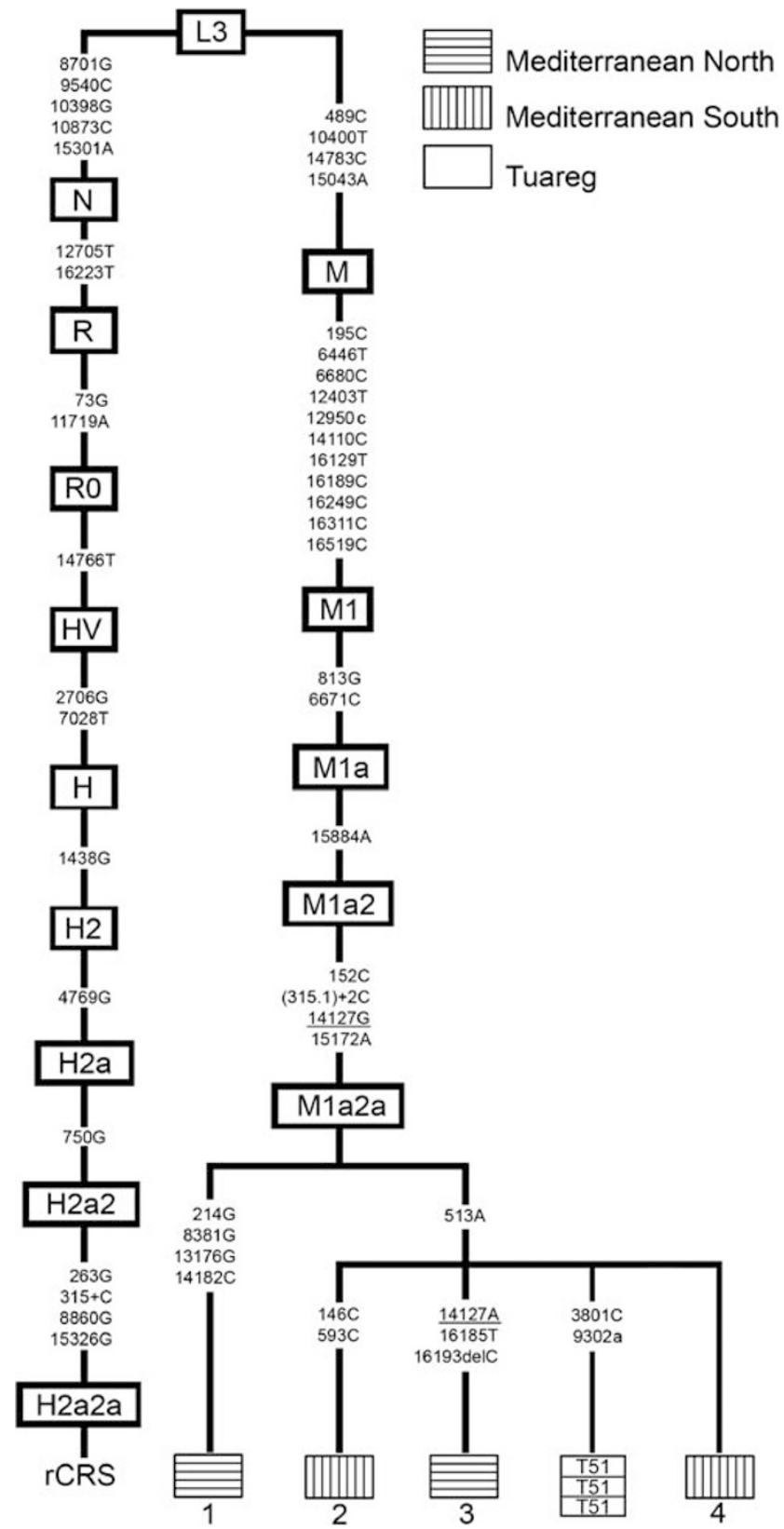

Figure 3 Phylogeny of the complete M1a2a mtDNA sequences, including the ones from Tuaregs and the published so far. Integers represent transitions, and an upper case suffix indicates a transition while a lower case suffix indicates a transversion. Deletions are indicated by a 'del' following the deleted nucleotide position. Underlined nucleotide positions appear more than once in the tree.

coming from East Africa and Fulani nomads ${ }^{6}$ coming from West Africa. In fact, by performing complete mtDNA sequencing of the L3f3 lineage, specific for Chadic-speaking groups of the Chad Basin, Černý et al ${ }^{41}$ estimated a local demographic expansion during the Holocene period at about $8000 \pm 2500$ YBP. No doubt all populations arriving to the Sahel were further enriched by various admixtures of many other sub-Saharan lineages, an effect even more pronounced in the Chadic groups who adopted a sedentary lifestyle soon after their arrival to the fertile Chad Basin than in the Tuareg who remain nomadic until present.

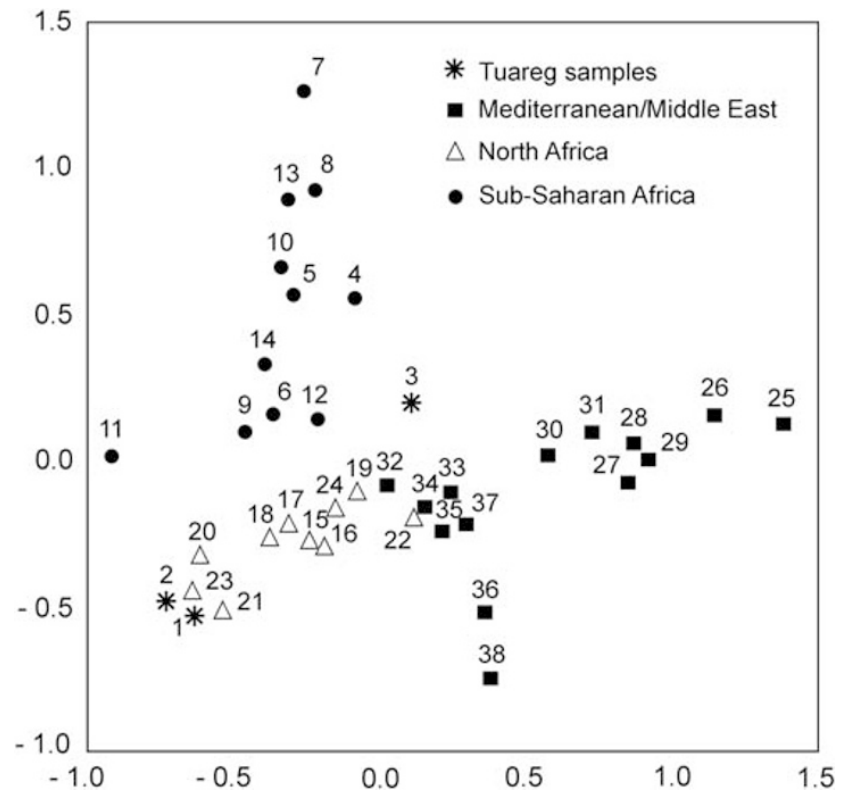

Figure $4 \mathrm{MDS}$ plot of $F_{\mathrm{ST}}$ distances calculated from NRY haplogroup frequencies. Codes for numbers are as in Supplementary Material SM2.

It is curious that, at least for the Tuareg maternal gene pool, there are no mtDNA lineages connected with the Neolithic expansion from the Near East despite being present in considerable frequencies in other North African populations. For example, the conservation of the high frequency and remarkable internal variability of T1 haplotypes within the distant and relatively isolated Egyptian oasis of el-Hayez led to an estimation of local expansion at around $5138 \pm 3633 \mathrm{YBP}^{37}$ There are no indications yet of the ages of local expansions in the more central and western regions of North Africa, which could contribute further insights for its absence in the Tuareg population as a whole.

Interestingly, for the Y chromosome, the dominant haplogroup in North Africa as well as the Tuareg is E1blblb. This haplogroup was associated with Neolithic diffusion in North Africa, with an age estimation of $2800-9800 \mathrm{YBP}^{45}$ but the lower resolution of the $\mathrm{Y}$ chromosome tree did not allow us to investigate this issue further. Nonetheless, disregarding whether they are in fact Neolithic, the ages for the mtDNA and Y chromosome lineages of North African origin observed in southern Tuareg are consistent with the same period, between 9000 and 3000 years ago.

\section{CONFLICT OF INTEREST}

The authors declare no conflict of interest.

\section{ACKNOWLEDGEMENTS}

The project was supported by the Grant Agency of the Czech Republic (Grant no. 206/08/1587), the Portuguese Fundação para a Ciência e a Tecnologia (PTDC/ANT/66275/2006 and Programa Operacional Ciência, Tecnologia e Inovação - Quadro Comunitario de Apoio III) (LP), Xunta de Galicia (Grupos Emerxentes; 2008/XA122), Fundación de Investigación Médica Mutua Madrileña (2006/CL370 and 2008/CL444) and Ministerio de Ciencia e Innovación (SAF2008-02971)(AS).

1 Lhote H: Les Touaregs du Hoggar (Ahaggar). Paris: Payot, 1955.

2 Cavalli-Sforza LL, Menozzi P, Piazza A: The History and Geography of Human Genes. Princeton, NJ: Princeton University Press, 1994. 
3 Watson E, Bauer K, Aman R, Weiss G, von Haeseler A, Paabo S: mtDNA sequence diversity in Africa. Am J Hum Genet 1996; 59: 437-444.

4 Watson E, Forster P, Richards M, Bandelt HJ: Mitochondrial footprints of human expansions in Africa. Am J Hum Genet 1997; 61: 691-704.

5 Ottoni C, Martinez-Labarga C, Loogväli EL et al: First genetic insight into Libyan Tuaregs: a maternal perspective. Ann Hum Genet 2009; 73: 438-448.

6 Černý V, Hájek M, Bromová M, Čmejla R, Diallo I, Brdička R: MtDNA of Fulani nomads and their genetic relationships to neighboring sedentary populations. Hum Biol 2006; 78: 9-27.

7 Álvarez-Iglesias V, Mosquera-Miguel A, Cerezo M et al: New population and phylogenetic features of the internal variation within mitochondrial DNA macro-haplogroup RO. PLoS One 2009; 4: e5112.

8 Cerezo M, Cerny V, Carracedo A, Salas A: Applications of MALDI-TOF MS to large-scale human mtDNA population-based studies. Electrophoresis 2009; 30: 3665-3673.

9 Brisighelli F, Capelli C, Álvarez-Iglesias V et al: The Etruscan timeline: a recent Anatolian connection. Eur J Hum Genet 2009; 17: 693-696.

10 Torroni A, Bandelt HJ, Macaulay $\mathrm{V}$ et al: A signal, from human mtDNA, of postglacial recolonization in Europe. Am J Hum Genet 2001; 69: 844-852.

11 Torroni A, Rengo C, Guida V et al: Do the four clades of the mtDNA haplogroup L2 evolve at different rates? Am J Hum Genet 2001; 69: 1348-1356.

12 Karafet TM, Mendez FL, Meilerman MB, Underhill PA, Zegura SL, Hammer MF: New binary polymorphisms reshape and increase resolution of the human $Y$ chromosomal haplogroup tree. Genome Res 2008; 18: 830-838.

13 Salas A, Richards M, De la Fé T et al: The making of the African mtDNA landscape. Am J Hum Genet 2002; 71: 1082-1111.

14 Kivisild T, Reidla M, Metspalu E et al: Ethiopian mitochondrial DNA heritage: tracking gene flow across and around the gate of tears. Am J Hum Genet 2004; 75: 752-770.

15 Behar DM, Villems R, Soodyall $\mathrm{H}$ et al: The dawn of human matrilineal diversity. Am J Hum Genet 2008; 82: 1130-1140.

16 Olivieri A, Achilli A, Pala M et al: The mtDNA legacy of the Levantine early Upper Palaeolithic in Africa. Science 2006; 314: 1767-1770.

17 Achilli A, Rengo C, Magri $C$ et al: The molecular dissection of mtDNA haplogroup $H$ confirms that the Franco-Cantabrian glacial refuge was a major source for the European gene pool. Am J Hum Genet 2004; 75: 910-918.

18 van Oven $\mathrm{M}$, Kayser $\mathrm{M}$ : Updated comprehensive phylogenetic tree of global human mitochondrial DNA variation. Hum Mutat 2009; 30: E386-E394.

19 Andrews RM, Kubacka I, Chinnery PF, Lightowlers RN, Turnbull DM, Howell N: Reanalysis and revision of the Cambridge reference sequence for human mitochondrial DNA. Nat Genet 1999; 23: 147.

20 Excoffier LGL, Schneider S: Arlequin ver. 3.0: an integrated software package for population genetics data analysis. Evol Bioinform Online 2005; 1: 47-50.

21 Rozas J, Rozas R: DnaSP version 3: an integrated program for molecular population genetics and molecular evolution analysis. Bioinformatics 1999; 15: 174-175.

22 Bandelt HJ, Forster P, Sykes BC, Richards MB: Mitochondrial portraits of human populations using median networks. Genetics 1995; 141: 743-753.

23 Mishmar D, Ruiz-Pesini E, Golik $\mathrm{P}$ et al: Natural selection shaped regional mtDNA variation in humans. Proc Natl Acad Sci USA 2003; 100: 171-176.

24 Forster P, Harding R, Torroni A, Bandelt HJ: Origin and evolution of Native American mtDNA variation: a reappraisal. Am J Hum Genet 1996; 59: 935-945.

25 Saillard J, Forster P, Lynnerup N, Bandelt HJ, Norby S: mtDNA variation among Greenland Eskimos: the edge of the Beringian expansion. Am J Hum Genet 2000; 67: 718-726.

26 Soares $\mathrm{P}$, Ermini L, Thomson $\mathrm{N}$ et al: Correcting for purifying selection: an improved human mitochondrial molecular clock. Am J Hum Genet 2009; 84: 740-759.

27 Finnila S, Lehtonen MS, Majamaa K: Phylogenetic network for European mtDNA. Am J Hum Genet 2001; 68: 1475-1484.

28 Herrnstadt C, Elson JL, Fahy E et al: Reduced-median-network analysis of complete mitochondrial DNA coding-region sequences for the major African, Asian, and European haplogroups. Am J Hum Genet 2002; 70: 1152-1171.

29 Pereira L, Richards M, Goios A et al: High-resolution mtDNA evidence for the late-glacial resettlement of Europe from an Iberian refugium. Genome Res 2005; 15: 19-24.
30 Cherni L, Fernandes V, Pereira JB et al: Post-last glacial maximum expansion from Iberia to North Africa revealed by fine characterization of mtDNA H haplogroup in Tunisia. Am J Phys Anthropol 2009; 139: 253-260.

31 Ennafaa $\mathrm{H}$, Cabrera VM, Abu-Amero $\mathrm{KK}$ et al: Mitochondrial DNA haplogroup $\mathrm{H}$ structure in North Africa. BMC Genet 2009; 10: 8.

32 Pereira L, Cunha C, Amorim A: Predicting sampling saturation of mtDNA haplotypes: an application to an enlarged Portuguese database. Int J Legal Med 2004; 118 : $132-136$.

33 Behar DM, Garrigan D, Kaplan ME et al: Contrasting patterns of $\mathrm{Y}$ chromosome variation in Ashkenazi Jewish and host non-Jewish European populations. Hum Genet 2004; 114: 354-365.

34 Plaza S, Calafell F, Helal A et al: Joining the pillars of Hercules: mtDNA sequences show multidirectional gene flow in the western Mediterranean. Ann Hum Genet 2003; 67: 312-328.

35 Černý V, Salas A, Hájek M, Žaloudková M, Brdička R: A bidirectional corridor in the Sahel-Sudan belt and the distinctive features of the Chad Basin populations: a history revealed by the mitochondrial DNA genome. Ann Hum Genet 2007; 71: 433-452.

36 Loogväli EL, Roostalu U, Malyarchuk BA et al: Disuniting uniformity: a pied cladistic canvas of mtDNA haplogroup $\mathrm{H}$ in Eurasia. Mol Biol Evol 2004; 21 : 2012-2021.

37 Kujanova M, Pereira L, Fernandes V, Pereira JB, Cerny V: Near eastern neolithic genetic input in a small oasis of the Egyptian Western Desert. Am J Phys Anthropol 2009; 140: 336-346.

38 Pereira L, Cunha C, Alves C, Amorim A: African female heritage in Iberia: a reassessment of mtDNA lineage distribution in present times. Hum Biol 2005; 77: 213-229.

39 Quintana-Murci L, Quach H, Harmant C et al: Maternal traces of deep common ancestry and asymmetric gene flow between Pygmy hunter-gatherers and Bantuspeaking farmers. Proc Natl Acad Sci USA 2008; 105: 1596-1601.

40 Pereira L, Macaulay V, Torroni A, Scozzari R, Prata MJ, Amorim A: Prehistoric and historic traces in the mtDNA of Mozambique: insights into the Bantu expansions and the slave trade. Ann Hum Genet 2001; 65: 439-458.

41 Černý V, Fernandes V, Costa MD, Hájek M, Mulligan CJ, Pereira L: Migration of Chadic speaking pastoralists within Africa based on population structure of Chad Basin and phylogeography of mitochondrial L3f haplogroup. BMC Evol Biol 2009; 9: 63.

42 Quintana-Murci L, Semino O, Bandelt HJ, Passarino G, McElreavey K, SantachiaraBenerecetti AS: Genetic evidence of an early exit of Homo sapiens sapiens from Africa through eastern Africa. Nat Genet 1999; 23: 437-441.

43 González AM, Larruga JM, Abu-Amero KK, Shi Y, Pestano J, Cabrera VM: Mitochondrial lineage M1 traces an early human backflow to Africa. BMC Genomics 2007; 8: 223.

44 Maca-Meyer N, González AM, Larruga JM, Flores C, Cabrera VM: Major genomic mitochondrial lineages delineate early human expansions. BMC Genet 2001; 2: 13.

45 Arredi B, Poloni ES, Paracchini S et al: A predominantly neolithic origin for Y-chromosomal DNA variation in North Africa. Am J Hum Genet 2004; 75 : 338-345.

46 Semino O, Magri C, Benuzzi G et al: Origin, diffusion, and differentiation of Y-chromosome haplogroups $\mathrm{E}$ and $\mathrm{J}$ : inferences on the neolithization of Europe and later migratory events in the Mediterranean area. Am J Hum Genet 2004; 74: 1023-1034.

47 Gallais J: Pasteurs et paysans du Gourma: la condition sahélienne. Paris: C.N.R.S.,, 1975.

48 Hill A, Randall S: Différences géographiques et sociales dans la mortalité infantile et juvenile au Mali. Population 1984; 39: 921-946.

49 Randall S, Winter M: The Reluctant Spouse and the Illegitimate Slave: Marriage, Household Formation, and Demographic Behaviour Amongst Malian Tamesheq from the Niger Delta and the Gourma. London: Overseas Development Institute, Agricultural Administration Unit,, 1986.

50 Torroni A, Achilli A, Macaulay V, Richards M, Bandelt HJ: Harvesting the fruit of the human mtDNA tree. Trends Genet 2006; 22: 339-345.

51 Coudray C, Olivieri A, Achilli A et al: The complex and diversified mitochondrial gene pool of Berber populations. Ann Hum Genet 2009; 73: 196-214.

52 Paul A: A History of the Beja Tribes of the Sudan. London: F. Cass, 1971.

Supplementary Information accompanies the paper on European Journal of Human Genetics website (http://www.nature.com/ejhg) 